\title{
PERENCANAAN INTERIOR MUSHOLA AL-ABROR, PARUNG PANJANG, BOGOR, JAWA BARAT
}

\section{Yunita Ardianti Sabtalistia ${ }^{1}$ dan Sintia Dewi Wulanningrum ${ }^{2}$}

\author{
${ }^{1}$ Jurusan Arsitektur dan Perencanaan, Universitas Tarumanagara \\ Email: yunitas@ft.untar.ac.id \\ ${ }^{2}$ Jurusan Arsitektur dan Perencanaan, Universitas Tarumanagara \\ Email: sintiaw@ft.untar.ac.id
}

\begin{abstract}
Mushola Al-Abror is located in Cluster The Village, Forest Hill Housing, Bogor, West Java. Currently the Al-Abror mosque is still under construction. The mushola exterior design exist before the construction stage. However, the mushola interior design still doesn't exist. Therefore it is necessary to make interior designs. The interior design concept used is Islamic architecture. The aim of this PKM is to plan the interior design of the Mushola Al-Abror based on the concept of Islamic architecture. The method of implementation was carried out in 3 stages over 6 months. The first stage is to conduct a field survey and coordinate with partners regarding interior design and ideas. The second stage is to submit interior design submissions in the form of work drawings and $3 D$ perspectives to partners. The third stage is the submission of the interior design results from the PKM team to partners. The prayer room for prayer is 8 $x 10$ meters in size. The prayer room is divided into 3 parts, namely: a prayer room for men, a prayer room for women, and a room for reciting Al-Qur'an. The prayer room is designed with many openings and windows on three sides in order to optimize the natural lighting and air circulation. The brown color is used in the carvings of the mihrab room and the partition dividing the prayer room for women. The brown color is chosen because it is a natural color. The carved motif on the top vent and the hexagonal mihrab room depicts a beehive. The specialty of bees and honey is implied in the verses of the Al-Qur'an. The carving motif on the partition dividing the prayer room is in the form of a leaf. The leaf motif was chosen because it is allowed to be used by Islamic architecture.
\end{abstract}

Keywords: Design, Interior, Islamic Architecture, Mushola

\begin{abstract}
ABSTRAK
Mushola Al-Abror berlokasi di Cluster The Village, Perumahan Forest Hill, Bogor, Jawa Barat. Saat ini mushola AlAbror masih dalam tahap pembangunan. Desain eksterior mushola sudah ada sebelum tahap pembangunan. Namun, desain interior mushola masih belum ada. Oleh karena itu perlu dibuat desain interiornya. Konsep desain interior yang digunakan adalah Arsitektur Islam. Berdasarkan latar belakang permasalahan tersebut maka tujuan PKM ini adalah membuat perencanaan desain interior mushola Al-Abror berdasarkan konsep arsitektur Islam. Metode pelaksanaan dilakukan dalam 3 tahap selama 6 bulan. Tahap pertama adalah melakukan survei lapangan dan berkoordinasi dengan mitra (panitia pembangunan Mushola Al-Abror) mengenai konsep dan ide desain interior. Tahap kedua adalah melakukan pengajuan desain interior berupa gambar kerja dan perspektif $3 D$ kepada mitra. Tahap ketiga adalah penyerahan hasil desain interior oleh tim PKM kepada mitra. Ruang ibadah mushola mempunyai ukuran 8 x 10 meter. Ruang ibadah tersebut dibagi menjadi 3 bagian, yaitu: ruang sholat pria, ruang sholat wanita, dan ruang mengaji untuk anak-anak. Ruangan mushola didesain dengan banyak bukaan dan jendela pada ketiga sisinya agar dapat mengoptimalkan pencahayaan alami dan sirkulasi udara. Warna coklat digunakan pada ukiran ruang mihrab dan partisi pembatas ruang sholat wanita. Warna coklat diplih karena merupakan warna alam. Motif ukiran pada ventilasi atas dan ruang mihrab berbentuk heksagonal yang menggambarkan sarang lebah. Keistimewaan lebah dan madu tersirat di dalam ayat Al-Qur'an. Motif ukiran pada partisi pembatas ruangan sholat berbentuk daun. Motif daun dipilih karena diperbolehkan penggunaannya dalam arsitektur Islam.
\end{abstract}

Kata kunci: Arsitektur Islam, Desain, Interior, Mushola

\section{PENDAHULUAN}

Mushola Al-Abror berlokasi di Cluster the Village, Perumahan Forest Hill, Parung Panjang, Bogor, Jawa Barat. Mushola ini berada di dalam lingkungan perumahan sehingga diperuntukkan sebagai tempat ibadah warga perumahan Forest Hill. Selain sebagai tempat ibadah, rencana ke depan mushola Al-Abror juga berfungsi sebagai tempat pengajian anak-anak pada waktu sore hari. Saat ini sedang berlangsung pembangunan Mushola Al-Abror. Gambar 1 menunjukkan eksterior Mushola Al-Abror. Tempat wudhu dan toilet terpisah dengan ruang sholat. Lokasi tempat wudhu dan toilet ada di sisi timur mushola (Gambar 2). 


\section{Gambar 1}

\section{Pembangunan Mushola Al-Abror}

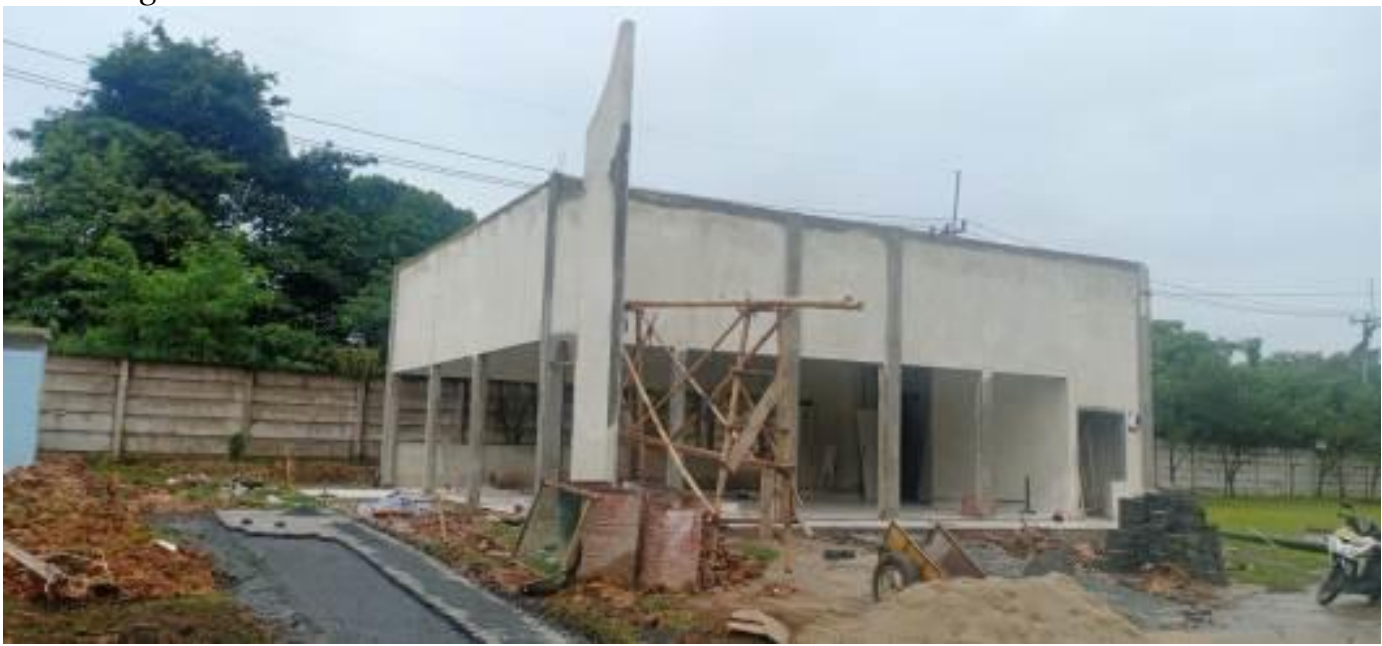

\section{Gambar 2}

Pembangunan Jalan Setapak Menuju Tempat Wudhu dan Mushola Al-Abror

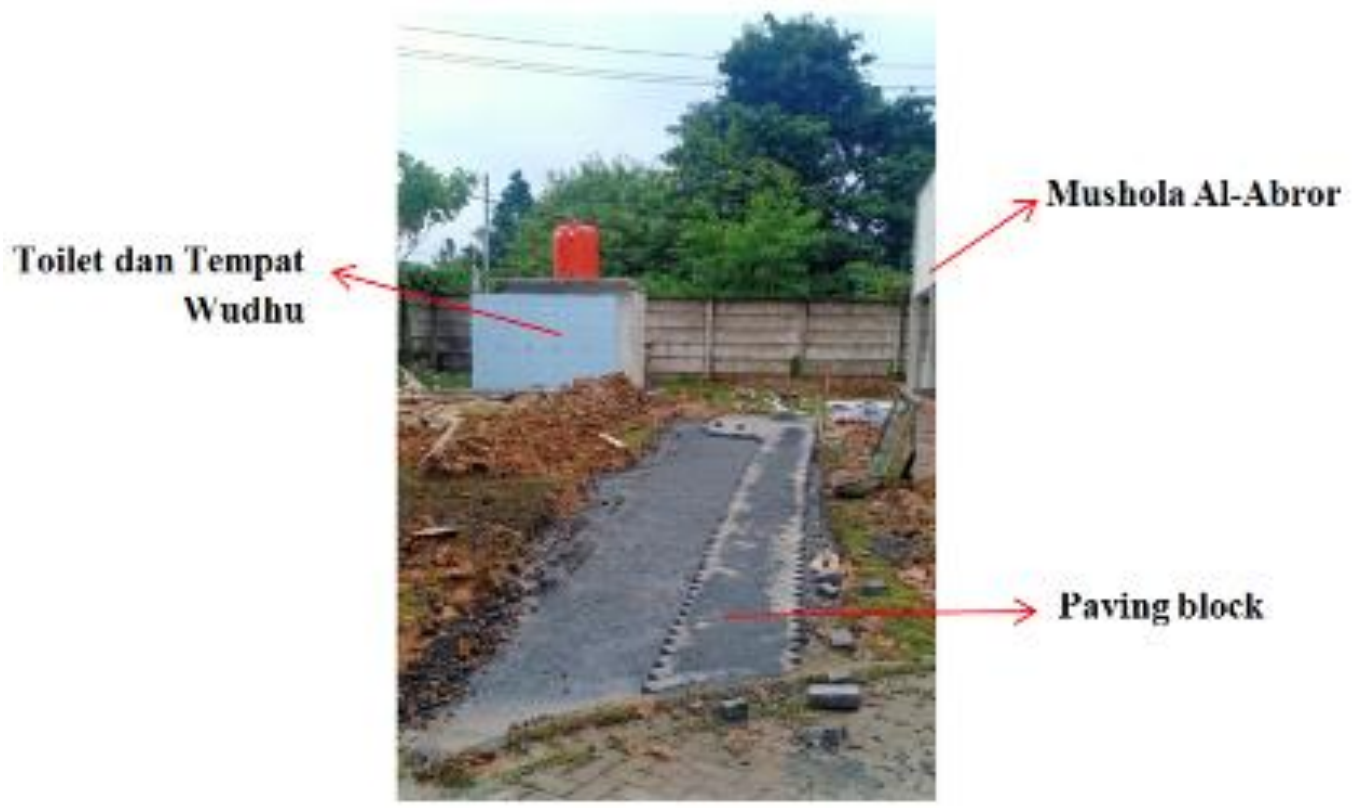

Mushola Al-Abror berfungsi sebagai tempat ibadah dan kegiatan Islam bagi perumahan Forest Hill. Musala (bahasa Arab: مصلّى) adalah ruangan, tempat atau rumah kecil menyerupai masjid yang digunakan sebagai tempat shalat dan mengaji bagi umat Islam (https://id.wikipedia.org/wiki/Musala). Musala juga sering disebut dengan surau atau langgar di beberapa daerah. Berbeda dengan masjid dari segi fungsi karena tidak bisa dipakai untuk salat berjamaah skala besar seperti halnya untuk salat Jumat, pada umumnya musala dipakai untuk salat berjamaah dengan skala kecil, kurang lebih 10-15 orang, tergantung muatan kapasitas musala tersebut. Biasanya musala tidak dilengkapi mimbar (Musala, 2020).

Bangunan yang serupa masjid yang tidak dipakai untuk shalat Jumat disebut mushalla. Kata ini menunjukkan isim makan dari "shalla" - "yushalli" - "shalatan" yang artinya tempat shalat. Dari pengertian tersebut dapat dipahami bahwa setiap masjid berarti juga mushalla, tetapi tidaklah 
setiap mushalla adalah masjid. Mushalla sering disebut dengan nama tajug, langgar, surau, meunasah dan sebagainya (Muslim, 2004).

Meskipun mushala mempunyai skala yang lebih kecil tapi fungsinya tidak jauh berbeda dengan masjid, yaitu: sebagai tempat shalat berjamaah, berdzikir, membaca al-Quran, dan kegiatan sosial keagamaan dalam upaya mengembangkan masyarakat Islam (Ridwanullah \& Herdiana, 2018). Bahkan saat ini keberadaan masjid menjadi sangat potensial terutama dalam memberdayakan umat islam untuk setiap aspek kehidupannya (Ridwanullah \& Herdiana, 2018).

Dalam konsep ajaran islam, arsitektur merupakan karya seni yang tidak lepas dari keindahan yang merujuk pada kebesaran Allah sebagai Sang Maha Pencipta (Fikriarini, 2010). Kita sebagai manusia hanyalah hamba yang kecil dan tidak berarti apa-apa dibandingkan dengan kebesaran Allah. Berdasarkan pemahaman tersebut maka banyak masjid didirikan dengan konsep megah dan mewah untuk menunjukkan kebesaran Allah.

Arsitektur islam merupakan wujud perpaduan antara kebudayaan manusia dan proses penghambaan diri seorang manusia kepada Tuhannya yang berada dalam keselarasan hubungan antara manusia, lingkungan, dan Penciptanya (Fikriarini, 2010). Arsitektur islam mengungkapkan hubungan geometris yang kompleks, hirarki bentuk dan ornamen, serta makna simbolis yang sangat dalam (Fikriarini, 2010).

Dalam membuat desain bangunan yang berfungsi untuk kegiatan islami setidaknya mengacu pada kaidah arsitektur islam. Adapun kaidah arsitektur islam ada 8 persyaratan, yaitu (Arsitektur Islam, 2020):

1. Di dalam dan luar bangunan tidak boleh ada gambar/ornamen makhluk hidup yang utuh

2. Di dalam dan luar bangunan terdapat ornamen yang mengingatkan kita kepada yang Maha Indah, Allah SWT

3. Hasil desain tidak ditujukan untuk pamer/kesombongan

4. Pengaturan ruang-ruang ditujukan untuk mendukung penjagaan akhlak dan perilaku

5. Posisi toilet tidak boleh menghadap atau membelakangi kiblat

6. Keberadaan bangunan tidak merugikan tetangga sekitar

7. Pembangunan sampai berdirinya bangunan seminimal mungkin tidak merusak alam

8. Menggunakan warna yang mendekatkan kepada Allah, seperti: warna-warna alam.

Saat ini mulai banyak bermunculan masjid-masjid yang tidak memiliki kubah. Salah satu masjid yang tidak memiliki kubah adalah Masjid Al-Irsyad karya Ridwan Kamil yang berlokasi di Kotabaru Parahyangan, Bandung Barat. Meskipun masjid Al-Irsyad tidak memiliki kubah namun sudah memenuhi 5 kriteria masjid berdasarkan syariat Islam dan sejarah masjid, yaitu: menghadap kiblat, bersih/suci, memiliki mihrab, memiliki batas-batas suci, dan tenang (Suhendar et al, 2020). Mushola Al-Abror juga tidak memiliki kubah tetapi juga sudah memenuhi 5 kriteria tersebut.

Mushola Al-Abror mempunyai ukuran ruang sholat 8 x 10 meter. Saat ini kondisi dinding, kolom, plafon ruang shalat masih dalam tahap persiapan pengecatan. Jika dilihat dari gambar 3 dapat dilihat bahwa desain ruang dalam masih sangat sederhana, hanya berupa ruangan kotak berukuran 10x10 meter. Masih belum ada penghias atau ornamen yang biasanya ada di dalam ruangan masjid atau mushola. Oleh karena itu tujuan PKM ini adalah membuat desain interior dengan konsep Arsitektur Islam. 


\section{Gambar 3}

Bagian Depan Ruang Sholat Mushola Al-Abror

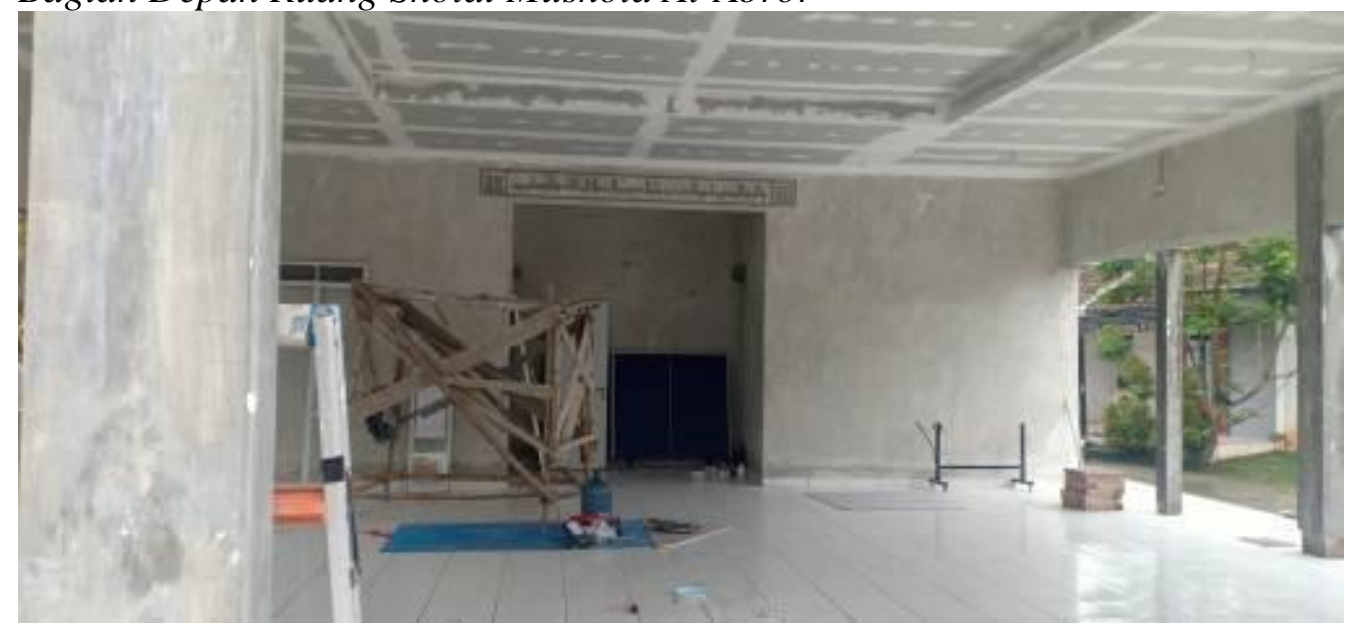

\section{METODE PELAKSANAAN PKM}

Kegiatan PKM ini bertujuan untuk membuat desain perencanaan interior Mushola Al-Abror dengan konsep Arsitektur Islam. Tahapan awal dimulai dengan studi literatur dan diakhiri dengan penyerahan hasil akhir PKM ke mitra (Gambar 4).

\section{Gambar 4}

Tahapan Pelaksanaan PKM

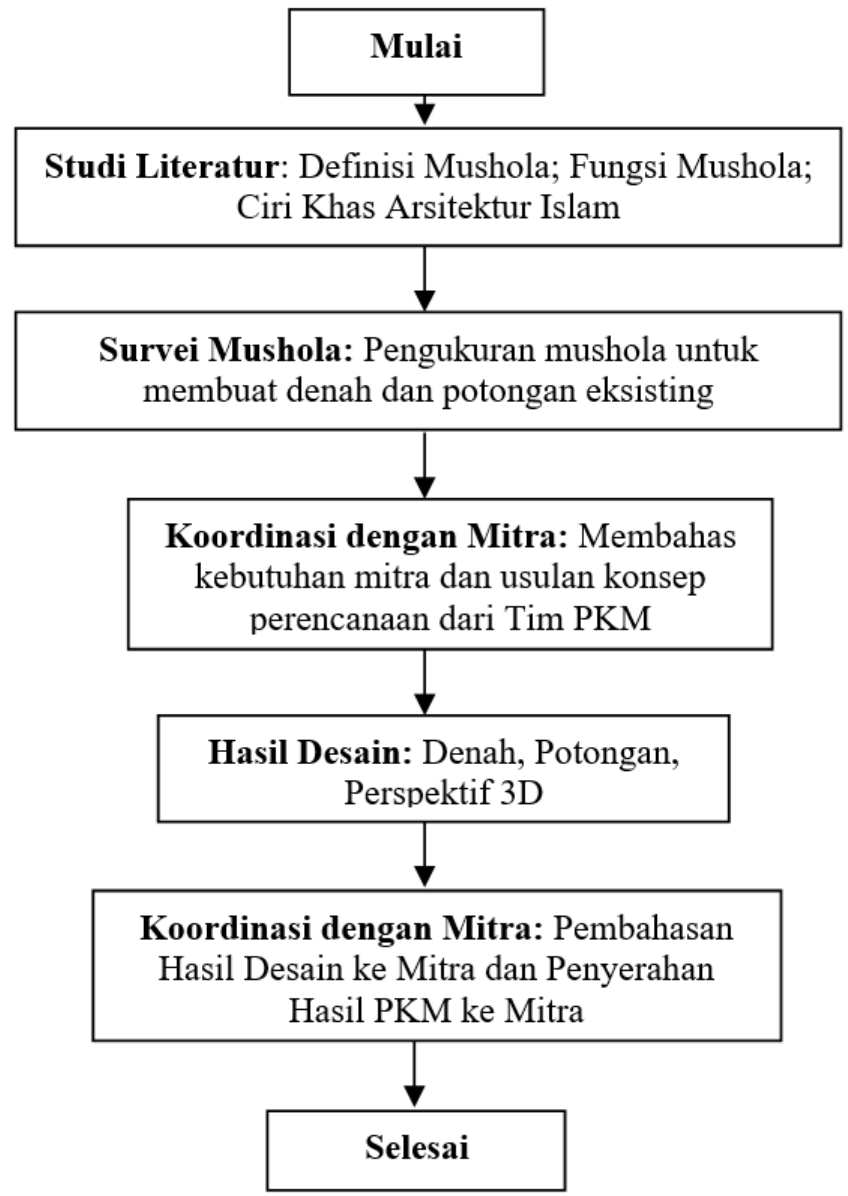


Untuk lebih detailnya, tahapan pelaksanaan kegiatan PKM ini adalah sebagai berikut:

1. Studi Literatur

Kajian literatur tentang definisi mushola, fungsi mushola, dan ciri khas arsitektur islam dari jurnal-jurnal dan internet

2. Survei Mushola

Pengukuran lokasi mushola dan pengumpulan foto-foto kondisi eksisting untuk mengetahui permasalahan mitra. Diskusi dan wawancara dengan Panitia Pembangunan Mushola Al-Abror dan beberapa warga juga dilakukan untuk mengetahui lebih jelas permasalahan yang ada

3. Koordinasi tim PKM dengan Mitra (Sebelum Perencanaan)

Setelah melakukan pengumpulan data primer dan sekunder selanjutnya koordinasi tim PKM perlu dilakukan untuk membahas tentang konsep dasar bangunan

4. Perencanaan Interior Mushola

Gambar yang dihasilkan meliputi gambar denah, potongan, dan perspektif 3D

5. Koordinasi tim PKM dengan Mitra (Setelah Perencanaan)

Gambar yang dihasilkan perlu dikoordinasikan dengan mitra (Panitia Pembangunan Mushola Al-Abror) agar mendapatkan kesepakatan desain yang sesuai dengan kebutuhan mitra.

\section{HASIL DAN PEMBAHASAN}

Ruangan sholat terbagi menjadi 3 bagian, yaitu: ruang sholat jamaah pria, ruang sholat jamaah wanita, dan ruang mengaji untuk anak-anak (Gambar 5). Ruang sholat jamaah wanita berukuran 3,33 x 3,64 meter. Pembatas ruang sholat wanita berupa partisi ukiran kayu dan tirai kain yang bisa dibuka tutup. Partisi ukiran kayu mempunyai tinggi 2,6 meter dari permukaan lantai. Pada sudut ruang sholat wanita terdapat rak gantung untuk mukena. Pada ruang mengaji terdapat papan tulis, rak buku, dan tempat penyimpanan meja lipat. Untuk mengoptimalkan pencahayaan alami dan sirkulasi udara, pada ketiga sisi dinding mushola dipasang jendela-jendela hidup, ventilasi atas, dan pintu geser kaca.

Pada ruang mihrab terdapat lafadz Allah (Gambar 6 dan 7). Bagian belakang lafadz Allah diberi lampu LED yang berwarna kehijauan agar dapat menerangi lafadz Allah. Pembatas mihrab dihiasi dengan ukiran kayu dan bacaan basmalah di dinding atas mihrab. Di tengah-tengah ruang sholat jamaah pria terdapat lampu kristal kotak dengan cahaya keputihan yang dipasang pada plafon yang bertingkat (drop ceiling). Gambar 8 menunjukkan suasana ruang sholat jamaah wanita. Jendela-jendela yang terpasang adalah jendela hidup agar angin bisa masuk ke dalam bangunan. Selain itu pada bagian atas jendela dipasang lubang-lubang ventilasi untuk memperlancar sirkulasi udara. Warna cat yang dipilih adalah warna putih karena warna putih dapat membuat suasana ruangan terkesan bersih dan membuat suasana menjadi lebih terang. Warna putih juga memberikan kontras dengan warna coklat pada ukiran kayu dan warna hijau pada sajadah.

Papan tulis putih (white board) dipasang pada dinding yang bagian belakangnya tidak ada jendela (Gambar 9). Rak buku mempunyai ukuran panjang $180 \mathrm{~cm}$, lebar $40 \mathrm{~cm}$, dan tinggi $65 \mathrm{~cm}$. Meja lipat bisa dibuka saat ada acara pengajian dan bisa ditutup jika acara sudah selesai. Tempat penyimpanan meja lipat ada di sudut ruangan. 


\section{Gambar 5}

Denah Mushola Al-Abror (Scale to Fit)

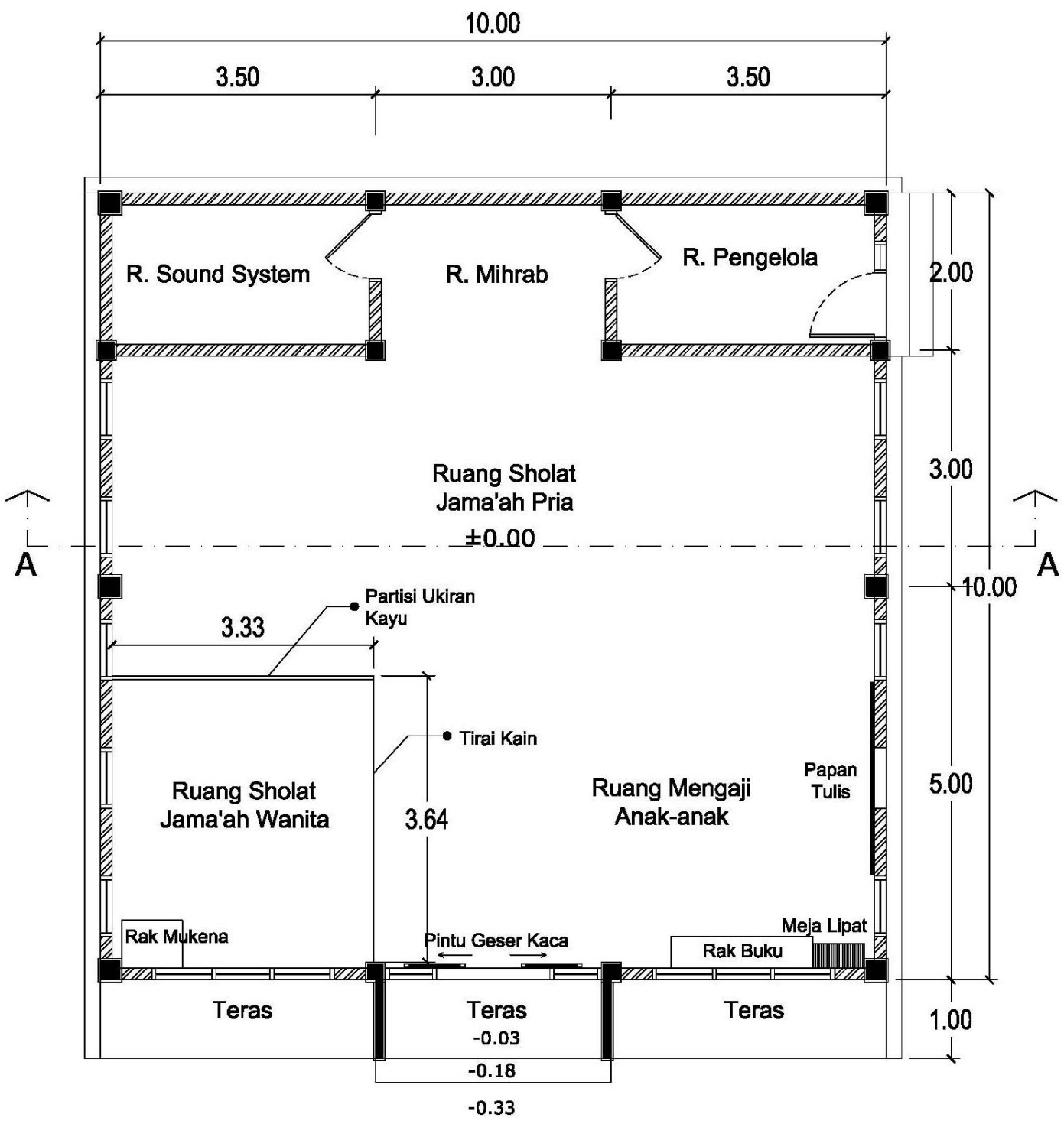

Bentuk motif ukiran kayu pada pembatas ruang mihrab dan krawangan GRC pada lubang-lubang ventilasi dibuat dengan pola heksagonal (segi enam) (Gambar 10). Bentuk heksagonal ini juga pernah diaplikasikan pada kegiatan PKM periode Ganjil tahun 2019 dengan judul "Perencanaan Eksterior Majelis Taklim Al Musa'adah, Parung Panjang, Bogor Berdasarkan Konsep Arsitektur Islam". Di alam semesta bentuk heksagonal biasa ditemui pada sarang lebah (Sabtalistia \& Wulanningrum, 2020). Keistimewaan sarang lebah dan madu disebutkan di dalam Al Qur'an pada Surat An-Nahl, ayat 68-69: "Dan Tuhanmu mewahyukan kepada lebah: 'Buatlah sarang-sarang di bukit-bukit, di pohon-pohon kayu, dan di tempat-tempat yang dibikin manusia,' kemudian makanlah dari tiap-tiap (macam) buah-buahan dan tempuhlah jalan Tuhanmu yang telah dimudahkan (bagimu). Dari perut lebah itu ke luar minuman (madu) yang bermacam-macam warnanya, di dalamnya terdapat obat yang menyembuhkan bagi manusia. Sesungguhnya pada yang demikian itu benar-benar terdapat tanda (kebesaran Tuhan) bagi orang-orang yang memikirkan" (Sabtalistia \& Wulanningrum, 2020). 


\section{Gambar 6}

Potongan A-A Mushola Al-Abror (Scale to Fit)

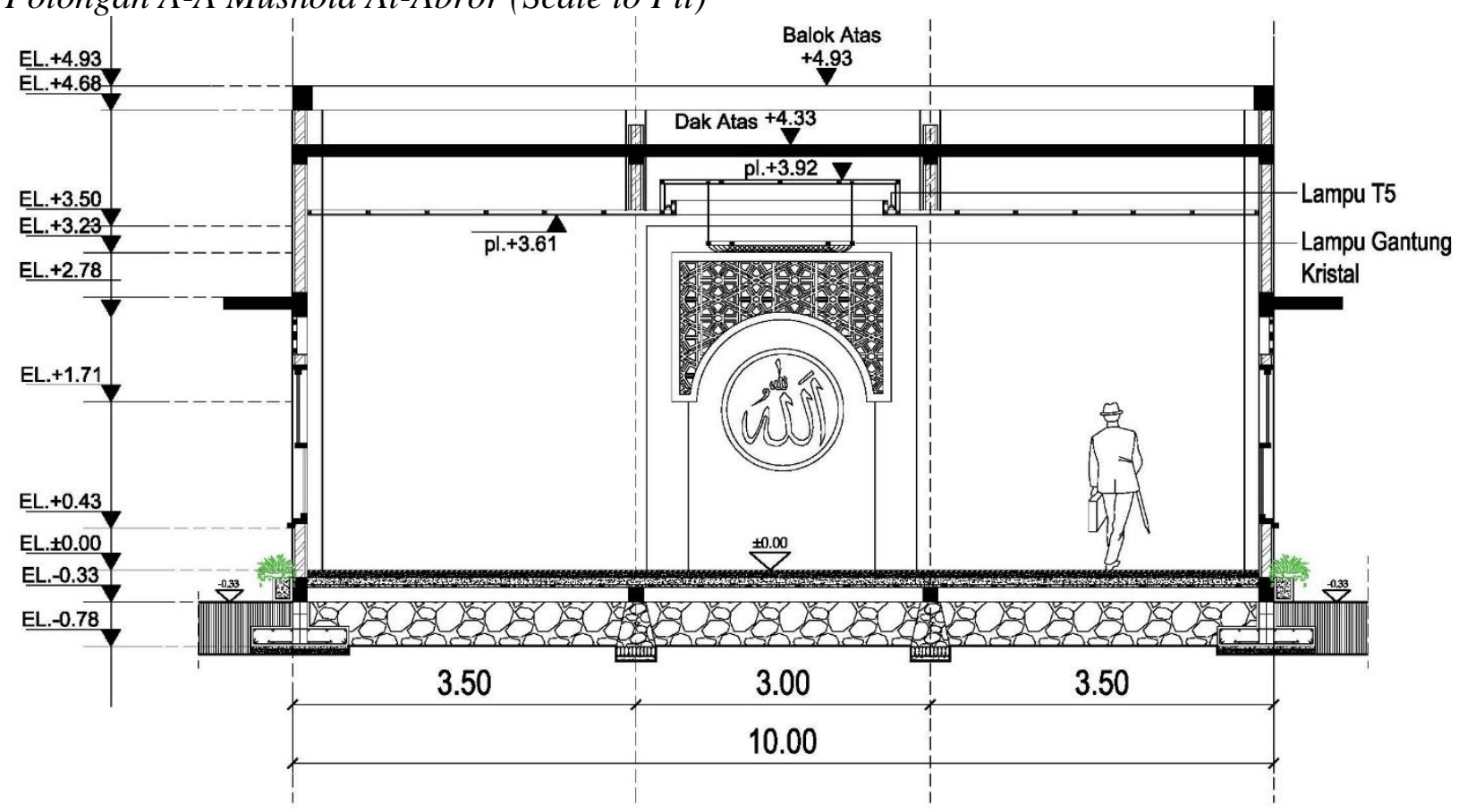

\section{Gambar 7}

Desain Mihrab Mushola Al-Abror dan Ruang Sholat Jamaah Pria

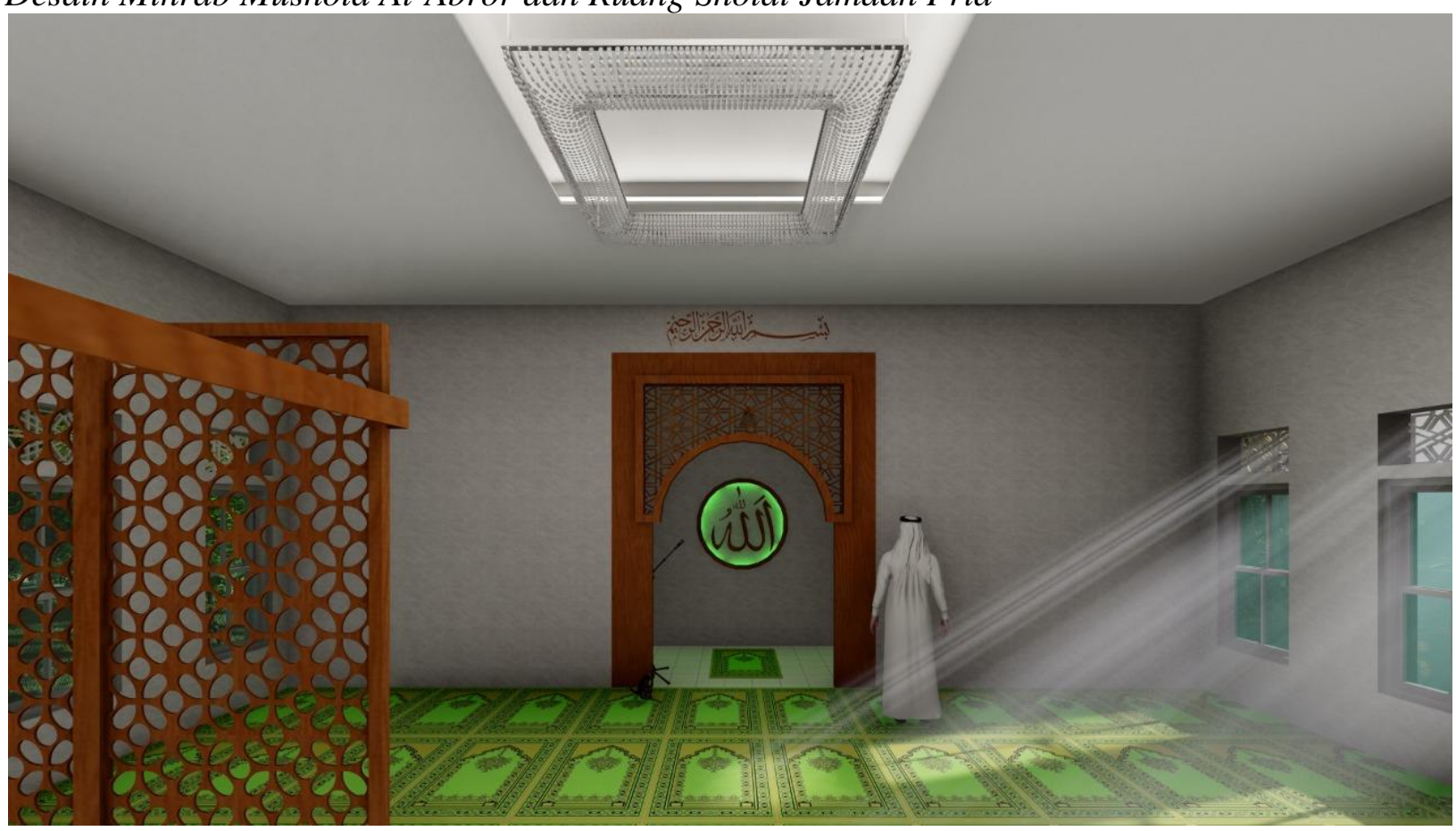




\section{Gambar 8}

\section{Desain Ruang Sholat Jamaah Wanita}

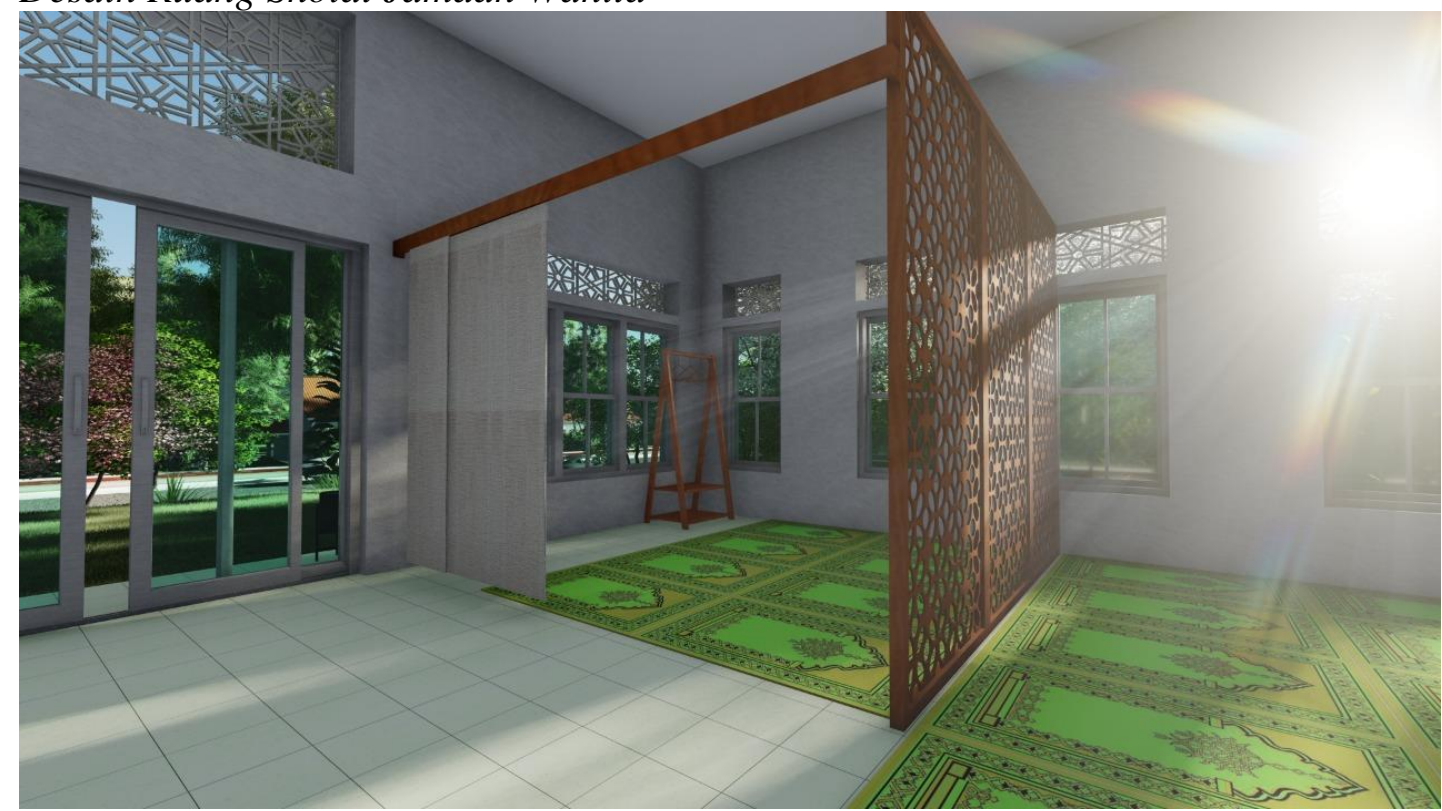

\section{Gambar 9}

\section{Desain Ruang Mengaji untuk Anak-anak}

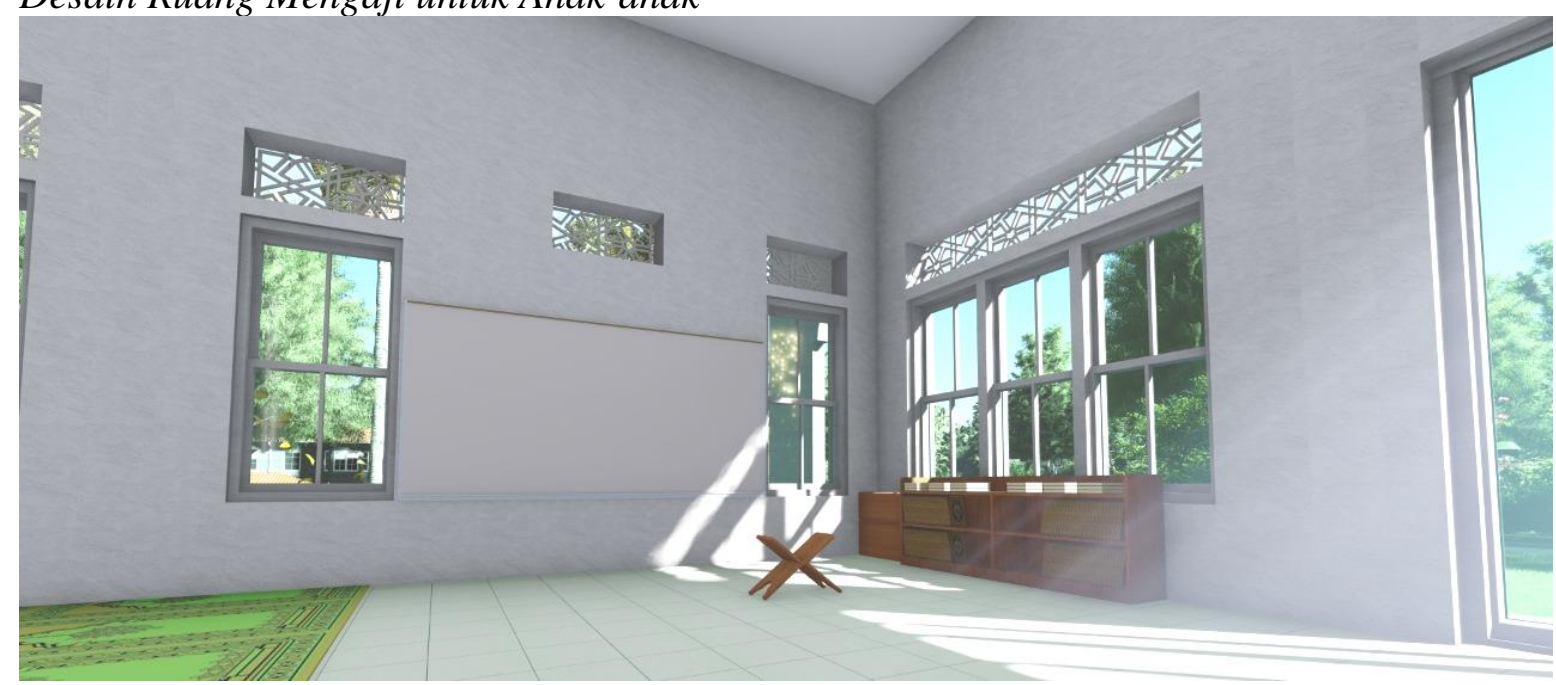

Berdasarkan kaidah arsitektur Islam ada 2 hal yang perlu diperhatikan pada saat mendesain bangunan Islami, yaitu: 1. tidak boleh ada ornamen manusia atau hewan ; 2. penggunaan warnawarna alam, seperti: warna coklat dan hijau (Arsitektur Islam, 2020). Partisi pembatas ruangan sholat wanita mempunyai motif bentuk daun (Gambar 11). Warna yang digunakan adalah coklat kayu yang merupakan warna-warna alam. 


\section{Gambar 10}

Bentuk Heksagonal pada (a) Pembatas Ruang Mihrab (b) Krawangan GRC pada Ventilasi Atas

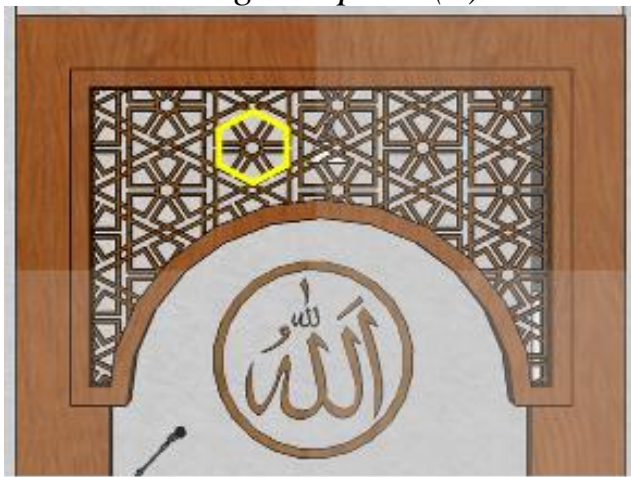

(a)

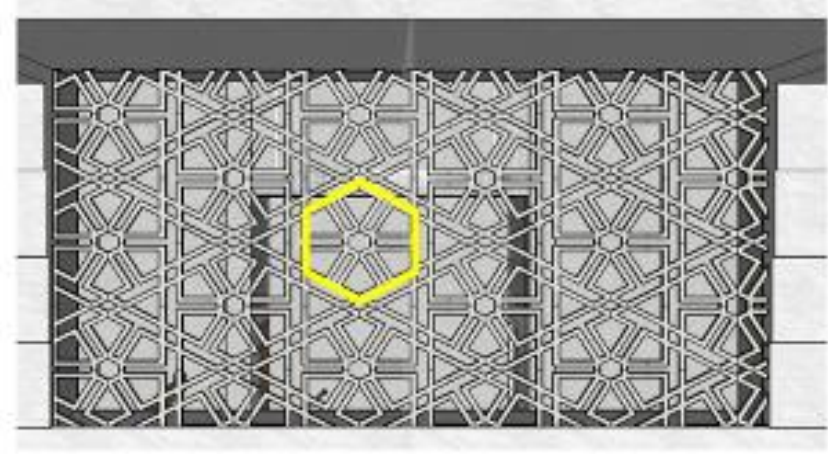

(b)

\section{Gambar 11}

Motif Daun pada Pembatas Ruang Sholat Jamaah Wanita

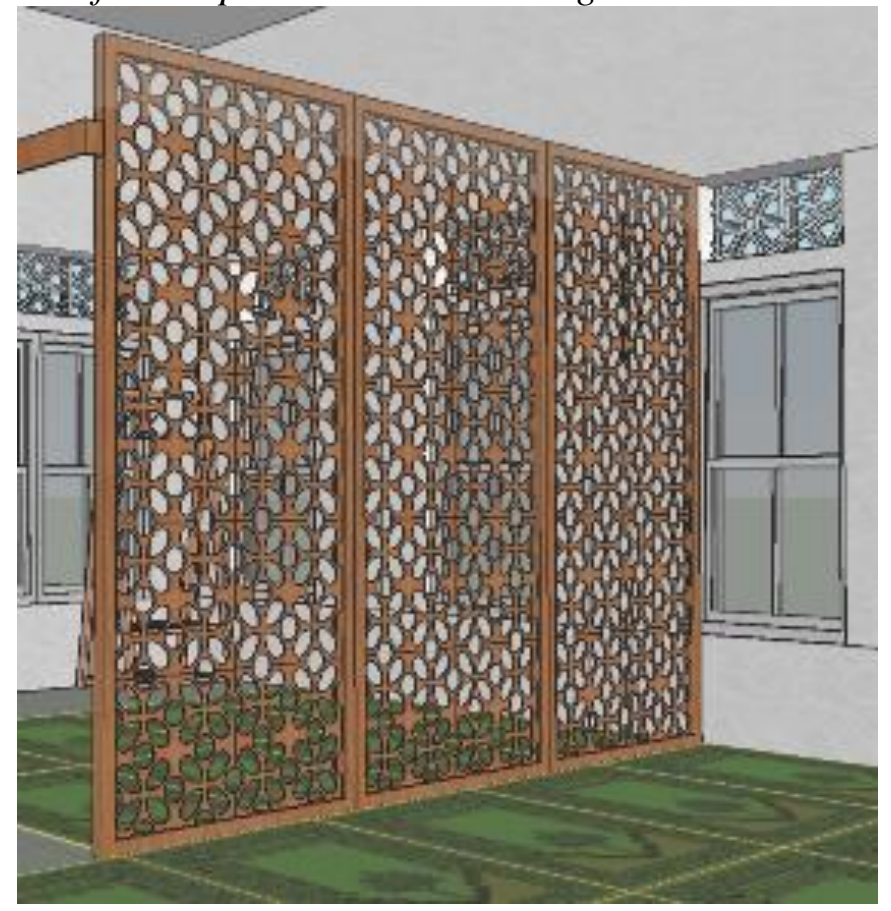

\section{KESIMPULAN DAN SARAN}

Mushola Al-Abror merupakan mushola yang diperuntukkan bagi warga Perumahan Forest Hill, Parung Panjang, bogor. Ruang ibadah mushola mempunyai ukuran 8 x 10 meter. Ruang ibadah tersebut dibagi menjadi 3 bagian, yaitu: ruang sholat pria, ruang sholat wanita, dan ruang mengaji untuk anak-anak. Ruangan mushola didesain dengan banyak bukaan dan jendela pada ketiga sisi dinding agar dapat mengoptimalkan pencahayaan alami dan sirkulasi udara. Dinding berwarna putih agar terkesan bersih dan terang. Warna coklat digunakan pada ukiran ruang mihrab dan partisi pembatas ruang sholat wanita. Warna coklat diplih karena merupakan warna alam. Motif ukiran pada ventilasi atas dan ruang mihrab berbentuk heksagonal yang menggambarkan sarang lebah. Keistimewaan lebah dan madu tersirat pada Surat An- Nahl ayat 68-69. Motif ukiran pada partisi pembatas ruangan sholat berbentuk daun. Motif daun dipilih karena diperbolehkan penggunaannya dalam arsitektur Islam. 
Ucapan Terima Kasih (Acknowledgement)

Pada kesempatan ini penulis mengucapkan terima kasih kepada Lembaga Penelitian dan Pengabdian kepada Masyarakat Universitas Tarumanagara dan Panitia Pembangunan Mushola AlAbror sehingga terlaksana kegiatan PKM ini.

\section{REFERENSI}

Arsitektur Islam. (6 April 2020). Wikipedia. https://id.wikipedia.org/wiki/Arsitektur_Islam

Fikriarini, A. (2010). Arsitektur Islam: Seni Ruang dalam Peradaban Islam. Jurnal El-Harakah, 12(3), 194-206.

Musala. (24 Oktober 2020). Wikipedia. https://id.wikipedia.org/wiki/Musala

Muslim, A. (2004). Manajemen Pengelolaan Masjid. Jurnal Aplikasi Ilmu-ilmu Agama, 5(2), $105-$ 114.

Ridwanullah, A. D. \& Herdiana, D. (2018). Optimalisasi Pemberdayaan Masyarakat Berbasis Masjid. Jurnal Ilmu Dakwah: Academic Journal for Homiletic Studies, 12(1), 82-98.

Sabtalistia, Y. A. \& Wulanningrum, S. D. (2020). Perencanaan Eksterior Majelis Taklim Al Musa'adah, Parung Panjang, Bogor Berdasarkan Konsep Arsitektur Islam. Jurnal Bakti Masyarakat Indonesia, 3(2), 496-505.

Suhendar, R., Fatimah, T., \& Trisno, R. (2020). Kajian Bentuk Masjid Tanpa Kubah Studi Kasus Masjid Al-Irsyad Bandung. Arsitekta: Jurnal Arsitektur dan Kota Berkelanjutan, 2(1), 1931. 